\title{
The Prevalence of Cationic Trypsinogen (PRSS1) and Serine Protease Inhibitor, Kazal Type 1 (SPINK1) Gene Mutations in Polish Patients with Alcoholic and Idiopathic Chronic Pancreatitis
}

\author{
Anita Gasiorowska - Renata Talar-Wojnarowska • \\ Leszek Czupryniak • Beata Smolarz • Hanna Romanowicz-Makowska • \\ Andrzej Kulig • Ewa Malecka-Panas
}

Received: 10 March 2010/ Accepted: 12 July 2010/Published online: 30 July 2010

(C) The Author(s) 2010. This article is published with open access at Springerlink.com

\begin{abstract}
Background The main cause of chronic pancreatitis (CP) is excessive alcohol consumption. On the other hand, only $5-10 \%$ of heavy drinkers develop chronic pancreatitis. We have only limited information regarding the pathogenic mechanism by which alcohol leads to the disease. Mutations of the PRSS1 and SPINK 1 have been mostly implicated in hereditary and idiopathic $\mathrm{CP}$, but their presence in other types of this disease have also been reported. Aims The aim of the study was to determine the frequency of PRSS1 and SPINK1 mutations in patients with chronic alcoholic (ACP) and idiopathic pancreatitis
\end{abstract}

\author{
A. Gasiorowska $(\bowtie) \cdot$ R. Talar-Wojnarowska . \\ E. Malecka-Panas \\ Department of Digestive Tract Diseases, Medical University \\ of Lodz, Kopcinskiego 22, 90-153 Lodz, Poland \\ e-mail: anita@sofcom.pl \\ R. Talar-Wojnarowska \\ e-mail: renata.talar-wojnarowska@umed.lodz.pl \\ E. Malecka-Panas \\ e-mail: ewuncia@poczta.onet.pl \\ L. Czupryniak \\ Diabetology and Metabolic Diseases, Medical University \\ of Lodz, Kopcinskiego 22, 90-153 Lodz, Poland \\ e-mail: bigosik@poczta.onet.pl \\ B. Smolarz · H. Romanowicz-Makowska · A. Kulig \\ Laboratory of Molecular Genetics, Institute of Polish Mother's \\ Memorial Hospital, Rzgowska 281/289, 93-338 Lodz, Poland \\ e-mail: smolbea@wp.pl \\ H. Romanowicz-Makowska \\ e-mail: hanna.romanowicz-makowska@umed.lodz.pl \\ A. Kulig \\ e-mail: andrzej.kulig@umed.lodz.pl
}

(ICP) as well as to investigate their relation to the clinical course of the disease.

Methods The study included 33 ACP and 14 ICP patients as well 46 healthy subjects. The diagnosis of $\mathrm{CP}$ was based on clinical data, ultrasound, and computed tomography. After isolation of DNA from peripheral blood two trypsinogen mutations were detected N29I and R122H by allelo-specific amplification polymerase chain reaction (ASA-PCR) and by the PCR-restriction fragment length polymorphism (RFLP). Beside this N34S mutation of SPINK1 was analyzed by PCR restriction fragment length polymorphism (PCR-RFLP).

Results PRSS1 mutations have been detected in $11(33 \%)$ patients with ACP. The frequency of the PRSS1 mutations was higher in patients with ACP than in controls (4.3\%) $(p<0.001)$. The frequency of PRSS1 mutation was present in $21.4 \%$ of ICP patients, which was significantly higher $(p<0.05)$ than in controls. Overall, six $(18 \%)$ SPINK1 mutations in ACP group have been detected. Among 14 patients with ICP, in four (28.6\%) of them SPINK1 has been detected. The same mutations have also been found in three (6.5\%) control subjects. The frequency of the N34S mutation was higher in patients with ICP than in the controls $(p<$ 0.05 ), but the frequency of N34S mutation did not differ between ACP and the control group. No relations have been detected between PRSS1 and SPINK1 mutations presence and clinical course and complications of CP.

Conclusions Those preliminary data suggest the high prevalence of SPINK1 and PRSS1 mutations in the Polish population, generally, as well as in CP patients. It may be speculated that those mutations contribute to the development of chronic pancreatitis, especially in patients with alcohol overindulgence.

Keywords Alcoholic chronic pancreatitis - Idiopathic chronic pancreatitis - SPINK1 · PRSS1 


\section{Introduction}

Chronic pancreatitis (CP) is a disease characterized by recurrent episodes of abdominal pain accompanied by progressive pancreatic exocrine and endocrine insufficiency $[1,2]$. In the Western countries, alcohol is generally considered an important risk factor for the development of chronic pancreatitis [3]. In addition, other metabolic, anatomical, obstructive, and autoimmune etiological factors have also been recognized [1, 4]. Furthermore, in recent years, several genetic risk factors for chronic pancreatitis have been identified. Nevertheless, around one-third of all patients have no etiological factor recognized, and these cases are classified as idiopathic chronic pancreatitis (ICP) [5]. Despite earlier suggestions that the clinical course of CP depends on its etiology, the final clinical and histological presentation of the disease is similar in most cases $[5,6]$.

The pathogenesis of $\mathrm{CP}$ is still only partially understood. Several mechanisms such as duct obstruction by protein plugs, direct toxicity of ethanol, or oxidative stress have been proposed [1, 2]. Furthermore, the exact mechanism of alcoholic pancreatitis is not known. Since only $5-10 \%$ of heavy drinkers develop the disease, numerous studies suggest that alcohol represents only a risk factor for developing pancreatic inflammation in genetic or environmentally predisposed subjects [7]. Whitcomb et al. [8] discovered mutations in the cationic trypsinogen gene (PRSS1) in families with hereditary pancreatitis, which stimulated the search for genetic factors predisposing to pancreatic disease. Some mutations in the PRSS1 gene are thought to prevent the inactivation of trypsin within the pancreas, leading to autodigestion and pancreatitis. Two mutations, R122H and N29I in the human cationic trypsinogen gene (PRSS1) have been detected in 14-68\% of the hereditary pancreatitis (HP) patients [8-12]. Mutations of those genes have been particularly implicated in hereditary pancreatitis, but their presence in disease of other etiologies have also been reported [13-15].

Pancreatic secretory trypsin inhibitor (PSTI), also known as serine protease inhibitor Kazal type1, (SPINK1), was suggested to be the first line of defense against premature trypsin activation in the pancreas [16]. Mutation in the SPINK1 gene was first shown to be associated with chronic pancreatitis in children and adolescents, and subsequently with many other forms of pancreatitis, including alcoholic pancreatitis [17-19]. In the former study, Witt and colleagues described that N34S mutation was present in 18 (19\%; six homozygotes and 12 heterozygotes) of 96 patients who did not carry any of the PRSS1 mutations [17]. In subsequent investigations, the N34S mutation of the serine protease inhibitor, Kazal type 1 (SPINK1), has been reported to have a connection with idiopathic and hereditary chronic pancreatitis [16, 20-22].

The aim of the study was to determine the frequency of PRSS1 and SPINK1 mutations in patients with alcoholic chronic pancreatitis (ACP) and idiopathic chronic pancreatitis (ICP) compared to healthy volunteers. We also reviewed the clinical data of $\mathrm{CP}$ patients and analyzed the severity of the disease with PRSS1 and SPINK1 mutations.

\section{Materials and Methods}

\section{Patients}

Patients were recruited from the Department of Digestive Tract Diseases, Medical University of Lodz. DNA analysis was obtained from blood samples and performed at the Laboratory of Molecular Genetics, Department of Pathology, Institute of Polish Mother's Memorial Hospital, Lodz, Poland.

A total of 47 patients with chronic pancreatitis were included in the present investigation: 33 with alcoholrelated disease, and 14 with idiopathic disease. All patients were Caucasian.

The diagnosis of $\mathrm{CP}$ was based on the following criteria [4]:

- presence of a typical history of recurrent attacks of pancreatitis

- anatomical abnormalities such as calcifications and/or pancreatic ductal irregularities present in ultrasound and computed tomography.

ACP (alcoholic chronic pancreatitis) was diagnosed in patients who consumed more than $80 \mathrm{~g} /$ day of alcohol (males) and at least $40 \mathrm{~g} / \mathrm{day}$ of alcohol (females) for 5 or more years, before the first symptoms of the disease [4].

ICP (idiopathic chronic pancreatitis) was diagnosed when possible etiological factors such as alcohol abuse and positive family history were absent [4]. Other possible risk factors for the development of chronic pancreatitis were evaluated through laboratory tests (hypercalcemia, hypertriglyceridemia) and by radiology (magnetic resonance cholangiopancreatography), including that of both the biliary and pancreatic ducts.

The associations of the analyzed mutations and clinical data have been evaluated. The following demographic and clinical data were analyzed: age, age of onset of $\mathrm{CP}$, gender, history of smoking, and endocrine insufficiency. The onset of chronic pancreatitis was defined as the initial manifestation-first episode of acute pancreatitis. For the purpose of this study, smokers were defined as those who smoked ten or more cigarettes per day for at least 2 years. The diagnosis of diabetes mellitus was made according to 
Table 1 Characteristics of the study population

\begin{tabular}{llll}
\hline & $\begin{array}{l}\text { Alcoholic } \\
\text { chronic } \\
\text { pancreatitis }(n=33)\end{array}$ & $\begin{array}{l}\text { Idiopathic } \\
\text { chronic } \\
\text { pancreatitis } \\
(n=14)\end{array}$ & $p$ \\
\hline $\begin{array}{l}\text { Sex }(\mathrm{M} / \mathrm{F}) \\
\begin{array}{l}\text { Mean age } \\
(\text { mean } \pm \mathrm{SD})\end{array}\end{array}$ & $29(88 \%) / 4(12 \%)$ & $6(43 \%) / 8(57 \%)$ & $<0.01$ \\
Age of onset (years) & $41(26-66)$ & $42 \pm 14$ & $\mathrm{NS}$ \\
\hline
\end{tabular}

WHO criteria, though in most patients diabetes usually was well established and treated some time prior to the enrollment to the study. Clinical data collected also included endoscopic (lithotripsy, endoscopic pancreatic or biliary stenting, and pseudocysts drainage) or surgical (pancreaticoduodenectomy, distal pancreatectomy, and pseudocyst drainage) treatment due to $\mathrm{CP}$ complications.

The demographic and clinical data of the 47 patients with chronic pancreatitis was divided into two groups: ACP and ICP, and are presented in Table 1. There were no differences in age between the two groups (ACP $46 \pm 9$ vs. ICP $42 \pm 14$ years). The majority of patients in the ACP group were male $(n=29 ; 88 \%)$ as compared to the ICP group $(n=6 ; 43 \%),(p<0.01)$. The median age of onset of the symptoms was 41 years (range 26-66) in patients with ACP, and 37 years (range 17-56) in patients with ICP. In the ICP group, in two patients the onset of disease was under 20 years.

The control group consisted of 46 healthy subjects ( 30 males, 16 females; mean $\pm \mathrm{SD}$ age: $35.0 \pm 17.9$ years, range: $21-77)$.

The study was undertaken under strict ethical guidelines and involved written consent of every participant. Patients were asked for informed consent to document their clinical data. The study was approved by the local ethics committee of the Medical University of Lodz.

Methods

\section{DNA Extraction}

Peripheral venous blood samples were obtained from all analyzed patients at the time of hospital admission and from the control group subjects. Genomic DNA was extracted from anticoagulated blood samples using the spin column method (QIAamp DNA Blood Mini Kits; Qiagen, Germany) according to the manufacturer's recommendations.

\section{PRSS1 Mutation Detection}

The R122H mutation was detected by the method PCRRFLP (polymerase chain reaction-restriction fragment length polymorphism) using specific primer sequences: $5^{\prime}$ GGT CCT GGG TCT CAT ACC TT $3^{\prime}$ and $5^{\prime}$ GTA ATG GGC ACT CGA AAT GT $3^{\prime}$. PCR was performed using $2 \mu \mathrm{l}$ of genomic DNA template, $1 \mathrm{U}$ of Taq polymerase (TaKaRa, BIOKOM), a $0.2 \mu \mathrm{M}$ concentration of each primer, $2.5 \mu \mathrm{l}$ of buffer, a $50 \mu \mathrm{M}$ concentration of each dNTP in a $25-\mu 1$ reaction volume. Thirty-five cycles of PCR were performed $\left(30 \mathrm{~s}\right.$ at $94^{\circ} \mathrm{C}, 30 \mathrm{~s}$ at $60^{\circ} \mathrm{C}, 30 \mathrm{~s}$ at $72^{\circ} \mathrm{C}$ ) and final extension for $5 \mathrm{~min}$ at $72^{\circ} \mathrm{C}$ in an automated thermal cycler GeneAmp PCR 2400 (Perkin Elmer, Norwalk, USA). The PCR products were then digested with restriction endonulcease $\mathrm{B} b r \mathrm{PI}$ for $2 \mathrm{~h}$ at $37^{\circ} \mathrm{C}$. The digested amplification products were electrophoresed on $7 \%$ polyacrylamide gel (PAGE) and stained with ethidium bromide, generating two fragments of $327 \mathrm{bp}$ and $228 \mathrm{bp}$. After digestion, the obtained product had an additional length of $208 \mathrm{bp}$.

The N29I mutation of exon 2 was detected by the PCR amplification using specific primer sequences: $5^{\prime}$ CCAT CTTACCCAACCTCAGTAG $3^{\prime}$ and $5^{\prime}$ TGATGACAGATCGTTGGGGGCTAGA $3^{\prime}$. The reaction program was as follows: an initial denaturation for $5 \mathrm{~min}$ at $94^{\circ} \mathrm{C}$, and an additional 35 cycles of $30 \mathrm{~s}$ denaturing at $94^{\circ} \mathrm{C} ; 30 \mathrm{~s}$ of hybridization for $30 \mathrm{~s}$ at $56^{\circ} \mathrm{C}, 45 \mathrm{~s}$ of primer extension at $72^{\circ} \mathrm{C}$; and a final extension for $10 \mathrm{~min}$ at $72^{\circ} \mathrm{C}$ in an automated thermal cycler GeneAmp PCR 2400 (Perkin Elmer, Norwalk, USA). The products were then digested with restriction endonulcease Sau3A. PCR-amplified products were electrophoretically separated on $7 \%$ polyacrylamide gel (PAGE) and stained with ethidium bromide. In the presence of N29I mutation, two bands of 207 and $23 \mathrm{bp}$ were seen, whereas only one band of $1,018 \mathrm{bp}$ was seen on the gel.

\section{SPINK1 Mutation Detection}

DNA samples from the patients and the control subjects were analyzed for a common mutation of SPINK1. The N34S mutation of exon 3 was detected by PCR-restriction fragment length polymorphism (RFLP) using specific primer sequences: $5^{\prime}$ TTC TGT TTA ATT CCA TTTTT AGG CCA AAT GCT GCA $3^{\prime}$ and $5^{\prime}$ GGC TTTT ATC ATA CAA GTG ACT TCT $3^{\prime}$. The primers were designed to introduce a PstI endonuclease restriction site in sequences containing the $\mathrm{N} 34 \mathrm{~S}$ mutation and $\mathrm{B} s r \mathrm{DI}$ endonuclease restriction site in wild-type sequences. PCR was performed using $2 \mu \mathrm{l}$ of genomic DNA template, $1 \mathrm{U}$ of Taq polymerase (TaKaRa, BIOKOM), a $0.2 \mu \mathrm{M}$ concentration of each primer, $2.5 \mu \mathrm{l}$ of buffer, a $50 \mu \mathrm{M}$ concentration of each $\mathrm{dNTP}$, and $25-\mu \mathrm{l}$ reaction volume. Thirty-five cycles of PCR were performed $\left(30 \mathrm{~s}\right.$ at $94^{\circ} \mathrm{C}, 30 \mathrm{~s}$ at $60^{\circ} \mathrm{C}$, and $60 \mathrm{~s}$ at $74^{\circ} \mathrm{C}$ ) in an automated thermal cycler GeneAmp PCR 2400 (Perkin Elmer, Norwalk, USA). The PCR 
products were then digested with restriction endonulcease PstI and BsrDI. Undigested amplification products were $320 \mathrm{bp}$ long. After digestion with PstI, a product of $286 \mathrm{bp}$ was obtained from mutant sequences, and an identical result was achieved from wild-type sequences after digestion with $B s r$ DI. Heterozygote samples produced products of both 320 and 286 bp after digestion with either endonuclease. PCR-amplified products were electrophoretically separated on $7 \%$ polyacrylamide gels (PAGE) and stained with ethidium bromide.

\section{Statistical Analysis}

Statistical analysis was performed using the STATISTICA for Windows package (8.0 version PL, \#AXXP2075488424 D60, StatSoft, Tulsa, Okla., USA). Differences between means of continuous variables (e.g., age) were analyzed by Student's $t$ test for unpaired data unless their distribution was not found normal with Kolmogorov and Lillefors' tests, in which case the Mann-Whitney $U$ test was used. Differences in mutations distribution were analyzed by the non-parametric $\chi^{2}$ test, when necessary-i.e., when cases number in a subgroup was $<5$-with Yates' correction. If cases number in a subgroup was zero, the exact Fisher test was employed. The measurements were expressed as means $( \pm \mathrm{SD})$. Values of $p<0.05$ were considered significant.

\section{Results}

\section{Mutational Analysis of PRSS1}

Analysis of the cationic trypsinogen gene revealed 14 mutations in 11 patients $(23.4 \%)$ among 47 individuals with chronic pancreatitis and two mutations $(4.3 \%)$ in the control group.

Generally, in the ACP group, 11 PRSS1 mutations were found in eight patients. In the ICP group, three PRSS1 mutations were carried by three patients. The cationic trypsinogen $\mathrm{R} 122 \mathrm{H}$ mutation affected seven patients $(21 \%)$ from the ACP group and two patients (14\%) from the ICP group, respectively. The next assessed PRSS1 mutation, namely N29I, was present in four patients with ACP (12\%) and in one patient with ICP (7\%).

Three patients from the ACP (9\%) group had both the $\mathrm{R} 122 \mathrm{H}$ and N29I cationic trypsinogen gene mutations.

The frequency of the PRSS1 mutations was higher in patients with ACP than in controls (33 vs. 4.3\%; $p<0.001$; OR was 11.0 (CI 2.47-47.73). The frequency of PRSS1 mutation was present in $21.4 \%$ of ICP patients which was significantly higher $(p<0.05)$ than in controls (4.3\%); OR was 6.0 (CI 1.05-33.93).
Otherwise, three patients, two from the ICP group and one from the ACP group had cationic trypsinogen gene (R122H) and N34S SPINK1 mutations.

\section{Mutational Analysis of SPINK1}

Mutational analysis of SPINK1 N34S in all chronic pancreatitis patients and controls was performed. Ten individuals with $\mathrm{CP}(21.3 \%)$ and three $(6.5 \%)$ from the control group carried the $\mathrm{N} 34 \mathrm{~S}$ mutation $(p>0.05)$.

Among the CP group, in six patients (18\%) with alcoholic CP and four patients $(28.6 \%)$ with idiopathic CP N34S mutation of the SPINK1 was detected. The frequencies of the N34S mutation in patients with ACP and ICP were similar. However, the frequency of the N34S mutation was higher in patients with ICP than in controls $(p<0.05)$. Odds ratio $(\mathrm{OR})$ for the $\mathrm{N} 34 \mathrm{~S}$ mutation occurrence in idiopathic $\mathrm{CP}$ was 5.73 ; $95 \%$ confidence interval (CI): 1.22-26.96.

In both ACP and ICP patients, the frequency of heterozygotes and homozygotes was equal, three (9\%) and two $(14.3 \%)$, respectively. Two individuals from the ICP group (14\%) were heterozygous and two homozygous for the mutation. In the control group, one homozygote $(2 \%)$ and two heterozygotes $(4 \%)$ have been detected. The frequency of N34S heterozygote or homozygote did not differ between the ACP, ICP, or control groups.

The frequency of the PRSS1 and SPINK1 mutations in the different groups are summarized in Table 2.

\section{Clinical Courses of Chronic Pancreatitis and Mutations}

Moreover, we evaluated the clinical course of ACP and ICP depending on different mutations present (Tables 3, 4). We reviewed the clinical course, including diabetes mellitus, calcification, pseudocysts, changes of the main pancreatic duct, cholestasis, and therapeutic intervention.

We did not find any significant difference of the clinical course between the ACP patients with and without PRSS1 mutations. The frequency of diabetes, as well as the frequency of calcification, were not different between the SPINK1 mutation-positive and -negative ACP patients. Patients carrying the N34S mutation had the same frequency of abnormal main pancreatic duct and pseudocysts. Patients carrying the N34S mutation did not require surgical and/or endoscopic intervention more often than those without the mutations.

The difference between the frequency of diabetes in ICP patients with and without SPINK1 and PRSS1 mutations did not approach statistical significance. Four patients having the SPINK1 mutation and one individual carrying the $\mathrm{R} 122 \mathrm{H}$ mutation had severe pancreatitis as defined by morphological alterations in the pancreas, such as duct 
Table 2 Distribution of the PRSS1 and SPINK1 mutations in affected individuals and the control group

\begin{tabular}{|c|c|c|c|c|c|c|}
\hline & \multicolumn{3}{|l|}{$\mathrm{N} 34 \mathrm{~S}$} & \multicolumn{3}{|l|}{ PRSS1 } \\
\hline & Total & Heterozygotes & Homozygotes & Total & $\mathrm{R} 122 \mathrm{H}$ & N29I \\
\hline Alcoholic chronic pancreatitis (ACP) $(n=33)$ & $6(18 \%)$ & 3 & 3 & $11^{\mathrm{b}}(33 \%)$ & 7 & 4 \\
\hline Idiopathic chronic pancreatitis (ICP) $(n=14)$ & $4^{\mathrm{a}}(28.6 \%)$ & 2 & 2 & $3^{\mathrm{c}}(21.4 \%)$ & 2 & 1 \\
\hline Control group $(n=46)$ & $3^{\mathrm{a}}(6.5 \%)$ & 2 & 1 & $2^{\mathrm{b}, \mathrm{c}}(4.3 \%)$ & 0 & 2 \\
\hline
\end{tabular}

${ }^{a}$ Statistical difference between frequency of N34S mutation in ICP compared to the control group $(p<0.05)$

b Statistical difference between frequency of PRSS1 mutations in ACP compared to the control group $(p<0.01)$

${ }^{c}$ Statistical difference between frequency of PRSS1 mutations in ICP compared to the control group $(p<0.05)$

Table 3 Comparison of clinical data of ACP patients with and without SPINK1 and PRSS1 mutations $(p>0.05)$

\begin{tabular}{lllllll}
\hline & $\begin{array}{l}\text { Mutated } \\
\text { SPINK1 } \\
(n=6)\end{array}$ & $\begin{array}{l}\text { Mutation } \\
\text { negative } \\
(n=27)\end{array}$ & $p$ & $\begin{array}{l}\text { Mutated } \\
\text { PRSS1 } \\
(n=11)\end{array}$ & $\begin{array}{l}\text { Mutation } \\
\text { negative } \\
(n=22)\end{array}$ & $p$ \\
\hline Diabetes mellitus & 3 & 12 & NS & 8 & 7 & NS \\
Calcifications & 3 & 8 & NS & 6 & 5 & NS \\
Pseudocysts & 2 & 13 & NS & 6 & 9 & NS \\
Abnormal main pancreatic duct & 3 & 5 & NS & 3 & 5 & NS \\
Cholestasis & 2 & 9 & NS & 4 & 7 & NS \\
Endoscopic treatment & 2 & 11 & NS & 6 & 7 & NS \\
Surgical treatment & 2 & 5 & NS & 3 & 4 & NS \\
Chronic use of analgesics & 2 & 12 & NS & 8 & 6 & NS \\
\hline
\end{tabular}

Table 4 Comparison of clinical data of ICP patients with and without SPINK1 and PRSS1 mutations $(p>0.05)$

\begin{tabular}{lllllll}
\hline & $\begin{array}{l}\text { Mutated } \\
\text { SPINK1 } \\
(n=4)\end{array}$ & $\begin{array}{l}\text { Mutation } \\
\text { negative } \\
(n=10)\end{array}$ & $p$ & $\begin{array}{l}\text { Mutated } \\
\text { PRSS1 } \\
(n=3)\end{array}$ & $\begin{array}{l}\text { Mutation } \\
\text { negative } \\
(n=11)\end{array}$ & $p$ \\
\hline Diabetes mellitus & 0 & 2 & NS & 1 & 10 & NS \\
Calcifications & 3 & 4 & NS & 1 & 7 & NS \\
Pseudocysts & 1 & 1 & NS & 1 & 1 & NS \\
Abnormal main pancreatic duct & 0 & 7 & NS & 0 & 7 & NS \\
Cholestasis & 0 & 5 & NS & 1 & 4 & NS \\
Endoscopic treatment & 0 & 7 & NS & 1 & 6 & NS \\
Surgical treatment & 1 & 3 & NS & 0 & 4 & NS \\
Chronic use of analgesics & 2 & 2 & NS & 0 & 4 & NS \\
\hline
\end{tabular}

dilatations, calcifications, pseudocysts, or duct strictures. The structural pancreatic changes in imaging techniques were similar in both groups (with and without mutations). Furthermore, no specific association was noted between any therapeutic intervention used in ICP patients and gene mutations.

\section{Discussion}

Several studies have investigated the role of the cationic trypsinogen gene and serine protease inhibitor Kazal type1 as an etiologic factor of pancreatitis. To our knowledge, this is the first study to determine the frequency of mutations in the PRSS1 and SPINK1 in Polish adult patients with chronic pancreatitis. The results of our study suggest the high incidence of SPINK1 and PRSS1 mutations in Polish population generally as well as in CP patients. In the study of our population, the PRSS1 mutations were detected in eight (24\%) ACP patients and in three $(21 \%)$ ICP patients. However, N34S mutation was found in six (18\%) patients with ACP and four $(28.6 \%)$ patients of ICP.

In Poland, only in Polish Institute of Mother and Child in Warsaw, the chronic pancreatitis and acute recurrent pancreatitis (ARP) in children and their family members were analyzed focusing exclusively on the mutations screening of PRSS1, SPINK1, CFTR (Cystic Fibrosis 
Transmembrane Conductance Regulator) and AAT ( $\alpha 1$-antitrypsin) [23]. In this study, PRSS1 mutations were identified mainly in CP patients, whereas N34S SPINK1 mutation was present with comparable frequency in $\mathrm{CP}$ and ARP patients.

Whitcomb et al. [8] conducted extensive mutational analysis of cationic trypsinogen gene in hereditary pancreatitis (HP) patients and their families throughout the world. The first pathogenic mutation in the human cationic trypsinogen gene (protease serine 1; PRSS1), a missense mutation $(\mathrm{R} 122 \mathrm{H})$ in exon 3 was reported. Other mutations in this gene, also associated with hereditary pancreatitis such as N29I, A16V, R122C, and D22G, were observed by other groups [8, 9, 11-13].

Although the PRSS1 mutations have shown an involvement with HP, they can also be found in a variable incidence (0-19\%) in idiopathic chronic pancreatitis [13, $15,24]$. In our study, we found $\mathrm{R} 122 \mathrm{H}$ mutation in two patients (14\%) and N29I mutation in one patient (7\%) with idiopathic CP. The frequency of PRSS1 mutations in ICP patients was found to be significantly higher (21\%) compared to the control group $(4.3 \%)$. There was no evidence of a family history of pancreatitis or pancreatic cancer in our patients. Witt et al. [10], analyzing the complete coding region of the cationic trypsinogen gene, found the A16V mutation in $10 \%$ patients with idiopathic pancreatitis from Germany. None of these patients had a family history of CP. The authors concluded that evaluation of patients with CP should include genetic testing for mutations in the cationic trypsinogen gene even in the absence of a family history of pancreatitis. Similarly, Simon et al. [25] found a trypsinogen mutation in five of 50 patients with idiopathic pancreatitis from Munster University Hospital. All patients had the $\mathrm{R} 122 \mathrm{H}$ mutation. They also revealed that patients with trypsinogen mutations were significantly younger at disease onset (mean age: $14 \pm 3$ years) than the remaining cohort (38 \pm 2 years) of patients. Recently, Grocock et al. [26] described the phenotypes that are associated with A16V mutation of PRSS1, but they didn't find differences compared to affected individuals with R122H and N29I mutations.

There are, however, limited data regarding frequency of PRSS1 mutations in ACP patients from different ethnic groups. In a Brazilian study, no mutation in the PRSS1 gene was detected in patients with a family history of pancreatitis, but the E79K mutation in the PRSS1 gene change in exon 3 was identified in one patient $(1.56 \%)$ with alcohol-related chronic pancreatitis [27]. O'Reilly et al. [15], in a study from the United Kingdom, described the $\mathrm{R} 122 \mathrm{H}$ mutation in one patient from the ACP group $(2.8 \%)$, however the N29I, A16V and -28delTCC mutations were not detected in any of the study subjects. Teich et al. [28] from Germany did not find N21I and R117H mutations of the cationic trypsinogen gene assessing in leukocyte DNA, in pancreatic juice and in the pancreatic tissue DNA from patients with ACP. In other studies from India [19], the Netherlands [21], and from the USA [29], no cationic trypsinogen mutation genes were identified in any of the ACP patients. Despite the fact that several studies failed to detect greater frequency of the PRSS1 mutations in ACP patients, we have found these mutations in as much as $33 \%$ of ACP patients [14, 15, 30, 31].

The association between SPINK1 mutations and the incidence of chronic pancreatitis in alcoholics has been controversial. In several studies, the SPINK1 N34S mutation was reportedly slightly increased in patients with alcoholic pancreatitis as compared to controls [18, 21, 30, 32]. Witt et al. [33] reported a 5.8\% prevalence of $\mathrm{N} 34 \mathrm{~S}$ SPINK1 in ACP patients, thus implicating mutated SPINK1 in its pathogenesis. Recently, patients with acute pancreatitis were also evaluated and the SPINK1 gene mutation was found in $7.8 \%$ of patients - the majority of them had alcohol-induced AP [34]. However, in the study performed by Lempinen et al. [18], a higher frequency $(10 \%)$ of the SPINK1 N34S mutation in patients with alcoholic CP was detected. In contrast to these studies, Chandak et al. [19] found a highly significant prevalence of SPINK1 mutations in a cohort of ACP patients from India (26.8\%). On the other hand, in a Korean population, occurrence of the SPINK1 N34S mutation in control population and patients with alcoholic pancreatitis was less common than in Western reports [35]. These discrepancies might obviously result from the genetic diversity in different ethnic groups. In our study, the frequency of the SPINK1 mutation in ACP was $18 \%$, which was higher than that observed in several reports from Europe and the USA. The N34S mutation was detected in three patients $(6.5 \%)$ from our control group, which is higher than in other reports $(0-2.8 \%)$ [32, 36-38].

The frequency of the SPINK1 mutations in ICP showed a discrepancy in different reports ranging from $6.4 \%$ in French patients [39], 25\% of patients from Finland [18] to as high as $40 \%$ in patients from the USA and The European Registry of Hereditary Pancreatitis and Familial Pancreatic Cancer (EUROPAC) Recruitment [20]. In a study by Pfutzer et al. [20], seven homozygous (12\%) and 14 heterozygous $(25 \%) \mathrm{N} 34 \mathrm{~S}$ mutations in a series of 57 ICP patients were reported. These patients were recruited for genetic analysis in the United States and Europe but were negative for PRSS1 mutations. The authors suggested that the mutated SPINK1 gene behaves as a disease-modifier gene. Another study from Germany and Switzerland demonstrated a strong association of SPINK1 gene mutation and ICP, especially with the early onset type [40]. In our study, the frequency of SPINK1 mutations in patients with idiopathic CP was $28.6 \%$, which is in line 
with previous reports, and confirms the association of SPINK1 mutations with idiopathic CP [17, 20].

It remains unknown whether the SPINK1 and PRSS1 mutations have an impact on the clinical course of CP. Our study, with a relatively limited number of patients, failed to reveal any association between mutations and the more severe form of chronic pancreatitis. Similar results were observed in other studies, including patients with ACP with and without SPINK1 mutation from the USA [32]. The authors concluded that presence of genetic variations in the SPINK1 gene does not appear to have a dominant effect on the clinical phenotype of alcoholic pancreatitis. In another study in ICP patients, the disease course was similar with regard to the development of calcifications and exocrine and endocrine insufficiency in early onset ICP patients with or without a heterozygous SPINK1 mutation [40]. In contrast, Masamune et al. [41] have shown in patients with non-alcoholic pancreatitis that those carrying the N34S mutation presented with more severe disease compared to ones without SPINK1 mutations. This study confirmed the previous report by Pfutzer et al. [20] showing that the SPINK1 mutations predisposed patients to an earlier age of disease onset. Other authors found a tendency for the N34S mutation to be more common in patients with severe acute pancreatitis, but it failed to reach statistical significance [34]. Creighton et al. [41] evaluated the correlation of $\mathrm{R} 117 \mathrm{H}$ mutation and clinical data of CP. They showed that this mutation was associated with a more severe form of HP in terms of age at onset of symptoms and requirement for surgical intervention. Finally, it might be added that results of a study by Keim et al. [42] showed that progression of chronic pancreatitis was slightly more rapid in patients with SPINK1 mutations than in patients with cationic trypsinogen mutations. In comparison to alcoholic chronic pancreatitis patients, the PRSS1 associated disease revealed a lower frequency of calcification and diabetes.

Some unresolved issues remain, including the high frequency of PRSS1 mutations in our CP patients. There are many clinical similarities of symptoms between chronic alcoholic and hereditary pancreatitis. When the onset of symptoms in patients with the inherited disease is late, and when a familial relationship is not obvious, it may be difficult to differentiate the two forms of CP. It cannot be excluded that patients have relatives affected but not fully diagnosed. Although susceptibility to alcoholic pancreatic damage could be inherited, until now no clear association between any gene mutation(s) and occurrence of ACP in alcoholics has been reported. Perri et al. [30] performed mutation analysis on the PRSS1, the CFTR, and the SPINK1 genes in Italian patients with ACP compared to patients from the same geographical area who were affected by alcoholic liver disease without any clinically recognized pancreatic disease. This study shows that mutations in PRSS1, CFTR, and SPINK1 genes are only occasionally found in patients with $\mathrm{ACP}$, and their prevalence is not significantly increased in comparison to alcoholics who develop alcoholic liver disease.

In conclusion, the frequency of PRSS1 mutations in ICP and ACP patients in Poland was higher than that reported in previous European studies. The frequency of the SPINK1 N34S mutation in patients with idiopathic CP was similar to that in many earlier studies but was higher in Polish patients with alcoholic CP compared to other studies and populations. The latter finding could be associated with a significantly higher population frequency of the N34S mutation in Poland than in other geographical regions.

Acknowledgments There were no financial relationships with a commercial entity producing health-care related products and/or services relevant to this article.

Open Access This article is distributed under the terms of the Creative Commons Attribution Noncommercial License which permits any noncommercial use, distribution, and reproduction in any medium, provided the original author(s) and source are credited.

\section{References}

1. Steer ML, Waxman I, Freedman S. Chronic pancreatitis. $N$ Engl J Med. 1995;332:1482-1490.

2. Mergener K, Baillie J. Chronic pancreatitis. Lancet. 1997;350: $1379-1385$

3. Gullo L, Barbara L, Labò G. Effect of cessation of alcohol use on the course of pancreatic dysfunction in alcoholic pancreatitis. Gastroenterology. 1988;95:1063-1068.

4. Etemad B, Whitcomb DC. Chronic pancreatitis: diagnosis, classification, and new genetic developments. Gastroenterology. 2001; 120:682-707.

5. Layer P, Yamamoto H, Kalthoff L, Clain JE, Bakken LJ, DiMagno EP. The different courses of early- and late-onset idiopathic and alcoholic chronic pancreatitis. Gastroenterology. 1994;107: 1481-1487.

6. Shrikhande SV, Martignoni ME, Shrikhande M, Kappeler A, et al. Comparison of histological features and inflammatory cell reaction in alcoholic, idiopathic and tropical chronic pancreatitis. Br J Surg. 2003;90:1565-1572.

7. Bisceglie AM, Segal I. Cirrhosis and chronic pancreatitis in alcoholics. J Clin Gasteroenterol. 1984;6:199-200.

8. Whitcomb DC, Gorry MC, Preston RA, Furey W, et al. Hereditary pancreatitis is caused by a mutation in the cationic trypsinogen gene. Nat Genet. 1996;14:141-145.

9. Gorry MC, Gabbaizedeh D, Furey W, Gates LK, et al. Mutations in the cationic trypsinogen gene are associated with recurrent acute and chronic pancreatitis. Gastroenterology. 1997;113:1063-1068.

10. Witt H, Luck W, Becker M. A signal peptide cleavage site mutation in the cationic trypsinogen gene is strongly associated with chronic pancreatitis. Gastroenterology. 1999;117:7-10.

11. Truninger K, Köck J, Wirth HP, Muellhaupt B, et al. Trypsinogen gene mutations in patients with chronic or recurrent acute pancreatitis. Pancreas. 2001;22:18-23.

12. Rebours V, Boutron-Rualt MC, Schnee M, Ferec C, et al. The natural history of hereditary pancreatitis: a national series. Gut. 2009;58:97-103. 
13. Creighton J, Lyall R, Wilson DI, Curtis A, Charnley R. Mutations of the cationic trypsinogen gene in patients with chronic pancreatitis. Lancet. 1999;354:42-43.

14. Monaghan KG, Jackson CE, KuKuruga DL, Feldman GL. Mutation analysis of the cystic fibrosis and cationic trypsinogen genes in patients with alcohol-related pancreatitis. Am J Med Genet. 2000;94:120-124.

15. O'Reilly DA, Yang BM, Creighton JE, Demaine AG, Kingsnorth AN. Mutations of the cationic trypsinogen gene in hereditary and non-hereditary pancreatitis. Digestion. 2001;64:54-60.

16. Threadgold J, Greenhalf W, Ellis I, Howes N, et al. The N34S mutation of SPINK1 (PSTI) is associated with a familial pattern of idiopathic chronic pancreatitis but does not cause the disease. Gut. 2002;50:675-681.

17. Witt H, Luck W, Hennies HC, Classen M, et al. Mutations in the gene encoding the serine protease inhibitor, Kazal type 1 are associated with chronic pancreatitis. Nat Genet. 2000;25:213-216.

18. Lempinen M, Paju A, Kemppainen E, Kylanpaa ML, et al. Mutations N34S and P55S of the SPINK1 gene in patients with chronic pancreatitis or pancreatic cancer and in healthy subjects: a report from Finland. Scand J Gastroenterol. 2005;40:225-230.

19. Chandak GR, Idris MM, Reddy DN, et al. Absence of PRSS1 mutations and association of SPINK1 trypsin inhibitor mutations in hereditary and non-hereditary chronic pancreatitis. Gut. 2004; 53:723-728.

20. Pfutzer RH, Barmada MM, Brunskill APJ, Finch R, et al. SPINK1/PSTI polymorphisms act as disease modifiers in familial and idiopathic chronic pancreatitis. Gastroenterology. 2000;119: 615-623.

21. Drenth JP, te Morsche R, Jansen JB. Mutations in serine protease inhibitor Kazal type 1 are strongly associated with chronic pancreatitis. Gut. 2002;50:687-692.

22. Kuwata K, Hirota M, Sugita H, Kai M, et al. Genetic mutations in exons 3 and 4 of the pancreatic secretory trypsin inhibitor in patients with pancreatitis. J Gastroenterol. 2001;36:612-618.

23. Sobczynska-Tomaszewska A, Bak D, Oralewska B, Oracz G, et al. Analysis of CFTR, SPINK1, PRSS1 and AAT mutations in children with acute or chronic pancreatitis. J Pediatr Gastroenterol Hepatol. 2006;43:299-306.

24. Ockenga J, Stuhrmann M, Ballmann M, Teich N, et al. Mutations of the cystic fibrosis gene, but not cationic trypsinogen gene, are associated with recurrent or chronic idiopathic pancreatitis. Am J Gastroenterol. 2000;95:2061-2067.

25. Simon P, Weiss FU, Zimmer KP, Rand S, et al. Spontaneous and sporadic trypsinogen mutations in idiopathic pancreatitis. JAMA. 2002;288:2122.

26. Grocock CJ, Rebours V, Delhaye MN, Andrén-Sandberg A, et al. The variable phenotype of the p.A16V mutation of cationic trypsinogen (PRSS1) in pancreatitis families. Gut. 2010;59:357-363.

27. Bernardino ALF, Guarita DR, Mott CB, Pedroso MRA, et al. CFTR, PRSS1 and SPINK1 mutations in the development of pancreatitis in Brazilian patients. JOP. 2003;4:169-177.

28. Teich N, Mössner J, Keim V. Screening for mutations of the cationic trypsinogen gene: are they of relevance in chronic alcoholic pancreatitis? Gut. 1999;44:413-416.
29. Monaghan KG, Jackson CE, Kukuruga DL, Feldman GL. Mutation analysis of the cystic fibrosis and cationic trypsinogen genes in patients with alcohol-related pancreatitis. Am J Med Gen. 2000;94:120-124.

30. Perri F, Piepoli A, Stanziale P, Merla A, Zelante L, Andriulli A. Mutation analysis of the cystic fibrosis transmembrane conductance regulator (CFTR) gene, the cationic trypsinogen (PRSS1) gene, and the serine protease inhibitor, Kazal type 1 (SPINK1) gene in patients with alcoholic chronic pancreatitis. Eur J Hum Genet. 2003;11:687-692.

31. Teich N, Bauer N, Mossner J, Keim V. Mutational screening of patients with nonalcoholic chronic pancreatitis: identification of further trypsinogen variants. Am J Gastroenterol. 2002;97: 341-346.

32. Schneider A, Pfutzer RH, Barmada MM, Slivka A, Martin J, Whitcomb DC. Limited contribution of the SPINK1 N34S mutation to the risk and severity of alcoholic chronic pancreatitis: a report from the United States. Dig Dis Sci. 2003;48:1110-1115.

33. Witt H, Luck W, Becker M, Böhmig M, et al. Mutation in the SPINK1 trypsin inhibitor gene, alcohol use, and chronic pancreatitis. JAMA. 2001;285:2716-2717.

34. Tukiainen E, Kylänpää ML, Kemppainen E, Nevanlinna H, et al. Pancreatic secretory trypsin inhibitor (SPINK1) gene mutations in patients with acute pancreatitis. Pancreas. 2005;30:239-242.

35. Lee KH, Ryu JK, Yoon WJ, Lee JK, Kim YT, Yoon YB. Mutation analysis of SPINK1 and CFTR gene in Korean patients with alcoholic chronic pancreatitis. Dig Dis Sci. 2005;50: $1852-1856$.

36. Masamune A, Kume K, Shimosegawa T. Differential roles of the SPINK1 gene mutations in alcoholic and nonalcoholic chronic pancreatitis. J Gastroenterol. 2007;42:135-140.

37. Mora J, Comas L, Ripoll E, Gonçalves P, et al. Genetic mutations in a Spanish population with chronic pancreatitis. Pancreatology. 2009;9:644-651.

38. Kume K, Masamune A, Mizutamari H, Kaneko K, et al. Mutations in the serine protease inhibitor Kazal type 1 (SPINK1) gene in Japanese patients with pancreatitis. Pancreatology. 2005;5: 354-360.

39. Chen JM, Mercier B, Audrezet MP, Raguenes O, Quere I, Ferec C. Mutations of the pancreatic secretory trypsin inhibitor (PSTI) gene in idiopathic chronic pancreatitis. Gastroenterology. 2001;120: 1061-1064.

40. Truninger K, Witt H, Kock J, Kage A, et al. Mutations of the serine protease inhibitor, Kazal type 1 gene, in patients with idiopathic chronic pancreatitis. Am J Gastroenterol. 2002;97: 1133-1137.

41. Creighton J, Lyall R, Wilson DI, Curtis A, Charnley R. Mutations of the cationic trypsinogen gene in patients with hereditary pancreatitis. Br J Surg. 2000;87:170-175.

42. Keim V, Witt H, Bauer N, Bodeker H, et al. The course of genetically determined chronic pancreatitis. JOP. 2003;4: 146-154. 